\title{
Shigatoxin triggers thrombotic thrombocytopenic purpura in genetically susceptible ADAMTS13-deficient mice
}

\author{
David G. Motto, ${ }^{1}$ Anil K. Chauhan, ${ }^{2,3}$ Guojing Zhu, ${ }^{1}$ Jonathon Homeister, ${ }^{4}$ Colin B. Lamb, ${ }^{2}$ \\ Karl C. Desch,, ${ }^{1}$ Weirui Zhang, ${ }^{5}$ Han-Mou Tsai, ${ }^{6}$ Denisa D. Wagner, ${ }^{2,3}$ and David Ginsburg ${ }^{5,7,8,9}$ \\ ${ }^{1}$ Department of Pediatrics, University of Michigan, Ann Arbor, Michigan, USA. ${ }^{2}$ CBR Institute for Biomedical Research, Boston, Massachusetts, USA. \\ ${ }^{3}$ Department of Pathology, Harvard Medical School, Boston, Massachusetts, USA. ${ }^{4}$ Department of Pathology and 5Department of Human Genetics, \\ University of Michigan, Ann Arbor, Michigan, USA. ${ }^{6}$ Department of Internal Medicine, Albert Einstein College of Medicine, New York, New York, USA. \\ 7Department of Internal Medicine, University of Michigan, Ann Arbor, Michigan, USA. ${ }^{8}$ Howard Hughes Medical Institute, \\ Chevy Chase, Maryland, USA. 9 Life Sciences Institute, University of Michigan, Ann Arbor, Michigan, USA.
}

Thrombotic thrombocytopenic purpura (TTP) is a life-threatening illness caused by deficiency of the vWFcleaving protease ADAMTS13. Here we show that ADAMTS13-deficient mice are viable and exhibit normal survival, although vWF-mediated platelet-endothelial interactions are significantly prolonged. Introduction of the genetic background CASA/Rk (a mouse strain with elevated plasma vWF) resulted in the appearance of spontaneous thrombocytopenia in a subset of ADAMTS13-deficient mice and significantly decreased survival. Challenge of these mice with shigatoxin (derived from bacterial pathogens associated with the related human disease hemolytic uremic syndrome) resulted in a striking syndrome closely resembling human TTP. Surprisingly, no correlation was observed between plasma vWF level and severity of TTP, implying the existence of TTP-modifying genes distinct from vWF. These data suggest that microbe-derived toxins (or possibly other sources of endothelial injury), together with additional genetic susceptibility factors, are required to trigger TTP in the setting of ADAMTS13 deficiency.

\section{Introduction}

The life-threatening systemic illness thrombotic thrombocytopenic purpura (TTP) is characterized by sudden onset of the pentad of fever, hemolytic anemia, thrombocytopenia, neurological symptoms, and renal dysfunction (1). This clinical picture results from the abrupt and widespread deposition of platelet-rich thrombi in the small vessels of multiple organs, which is the pathologic hallmark of the disease (2). Although the incidence of TTP appears to be increasing, modern intensive therapy has decreased TTP mortality from $90 \%$ to under $20 \%$ (3). Morbidity also remains significant, as treatment carries considerable risks, including exposure to blood products obtained from multiple donors.

TTP results from loss of function of the recently described ADAMTS13 metalloprotease $(1,4)$. ADAMTS13 specifically cleaves $\mathrm{VWF}$, an adhesive multimeric plasma glycoprotein that serves as the initial link for the attachment of circulating blood platelets to sites of vascular injury (1). The largest and most adhesive forms of vWF may contain up to 100 individual subunits and are termed ultra-large vWF (UL-vWF) (5). If not proteolytically processed by ADAMTS13 to smaller forms, circulating UL-vWF is thought to trigger widespread spontaneous platelet aggregation, ultimately leading to overt TTP.

Loss of ADAMTS13 function can be due to either genetic deficiency (familial TTP) or inhibitory autoantibodies to ADAMTS13 (acquired TTP) (6-8). Acquired TTP primarily affects individuals

Nonstandard abbreviations used: HUS, hemolytic uremic syndrome; Stx, Shigatoxin; TTP, thrombotic thrombocytopenic purpura; UL-vWF, ultra-large vWF. Conflict of interest: The authors have declared that no conflict of interest exists. Citation for this article: J. Clin. Invest. 115:2752-2761 (2005). doi:10.1172/JCI26007. between 20 and 60 years of age (1). Plasma exchange is the treatment of choice, and approximately one-third of acquired TTP cases become chronic (9). Patients with the less-common familial form of TTP typically exhibit a chronic relapsing course and, unlike patients with acquired TTP, generally respond well to simple plasma infusion, usually without the need for plasma exchange (1).

Although familial TTP often manifests during infancy, about one-half of cases remains undiagnosed until mid-childhood or later, with rare ADAMTS13-deficient individuals still free of disease through the third decade of life (10). Family members with the same ADAMTS13 mutation(s) frequently demonstrate highly variable age of onset and disease severity (10), and both acquired and genetically deficient patients can be clinically recovered from an episode of TTP but still demonstrate UL-vWF multimers and severely decreased plasma ADAMTS13 activity $(7,11)$. These observations suggest that loss of ADAMTS13 activity and the associated increase in circulating UL-vWF may be necessary, but not sufficient, for the induction of a clinical episode of TTP, implying the existence of critical environmental triggers and/or genetic modifying factors for this disease.

Multiple ADAMTS13 mutations have been identified in familial TTP patients $(4,12,13)$. However, the absence of cases with clear null mutations has led to the hypothesis that complete deficiency of ADAMTS13 may be lethal. Consistent with this notion, individuals with familial TTP usually exhibit low levels of residual ADAMTS13 activity, potentially accounting for some of the phenotypic variability observed among patients with this disorder (4). However, differences in residual ADAMTS13 activity are unlikely to account for the observed variation among individuals within a given family, as these persons are expected to harbor the same ADAMTS13 mutations. To address the 


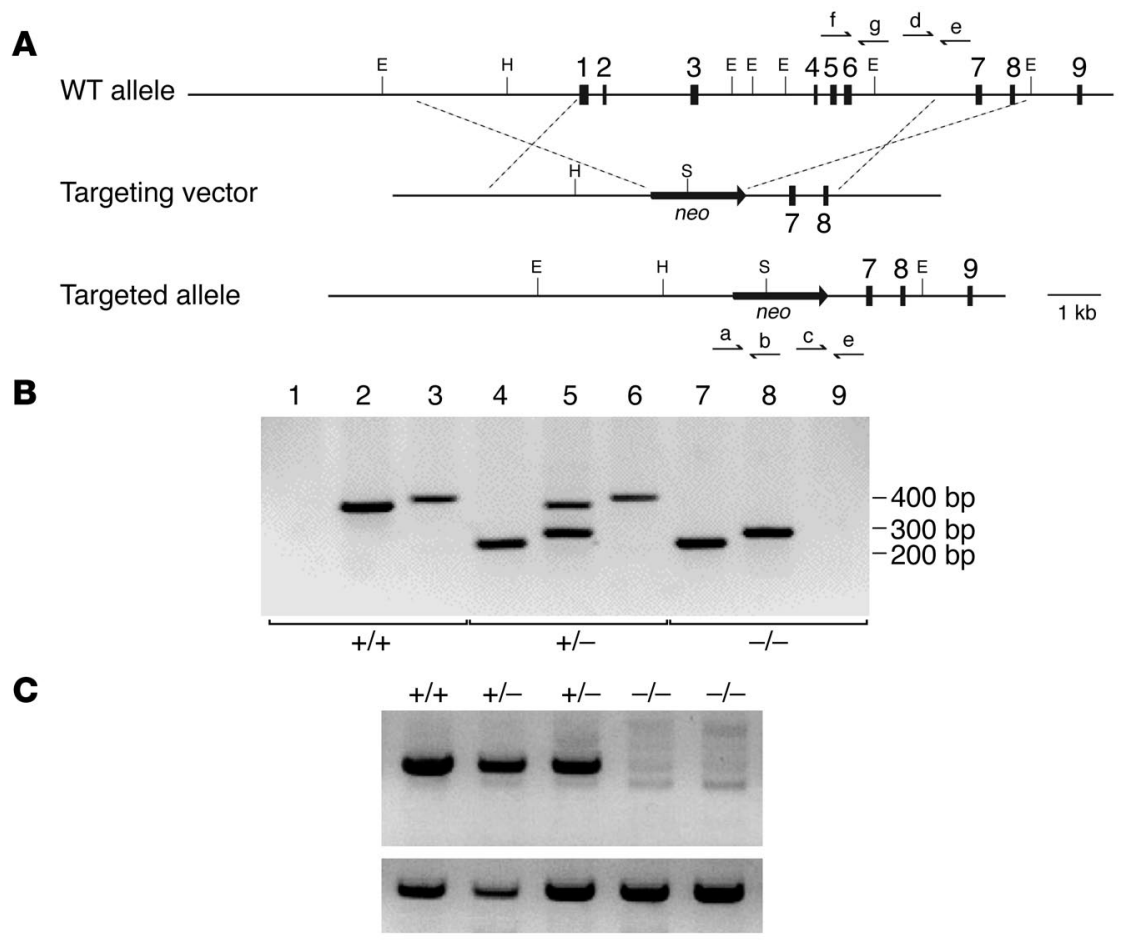

Figure 1

Generation of ADAMTS13-deficient mice. (A) Schematic diagrams of the wild-type and targeted Adamts 13 alleles and the targeting vector. Exons are indicated as numbered boxes. The locations of PCR primers used in B are indicated by lower-case letters and arrows. The locations of selected restriction sites are indicated by upper-case letters (E, EcoRI; H, Hindlll; and S, Spel). (B) Genomic PCR demonstrating correct targeting of the Adamts13 gene. Lanes 1, 4, and 7: primers $a+b$; lanes 2, 5, and 8: primers $c+d+e$; and lanes 3, 6, and 9: primers $f+g$. A 240-bp band specific for the Neo insertion is seen only in Adamts $13^{+/-}$and Adamts $13^{-/-}$mice (lanes 4 and 7 ); a 280 -bp band specific for the targeting vector is seen only in Adamts $13^{+/-}$and Adamts $13^{-1-}$ mice (lanes 5 and 8); a 370-bp specific for the wild-type allele is seen only in Adamts $13^{+/+}$and Adamts $13^{+/-}$mice (lanes 2 and 5); and a 400-bp band specific for deleted exon 6 is seen only in Adamts $13^{+/+}$and Adamts $13^{+/-}$mice (lanes 3 and 6 ) and is not seen in Adamts13-/- mice (lane 9). (C) RT-PCR of liver mRNA prepared from Adamts 13 B/129+//, Adamts13 $1 / 129+/$, and Adamts $13^{B / 129-/ /}$ mice. Primers specific for exons 1-6 of Adamts13 (upper panel) or vWF (lower panel) were used. Adamts13 exons 1-6 were readily detected in mRNA from Adamts $13^{B / 129+/+}$ and Adamts $13^{B / 129+/-}$ mice but were absent in mRNA from Adamts $13^{B / 29-/-}$ mice.

requirement for ADAMTS13 in normal hemostasis, and to further explore the pathogenesis of TTP in vivo, we generated ADAMTS13-deficient mice by gene targeting.

\section{Results}

ADAMTS13-deficient mice exhibit normal development and survival. The murine Adamts 13 gene was disrupted by replacing exons 1-6 of murine Adamts 13 with a neomycin resistance cassette (Figure 1A). Exons 1-6 contain the translation start site, signal peptide, propeptide, and most of the protease domain (including the active site cysteine residue). Thus, removal of these sequences should result in a nonfunctional protein. Disruption of Adamts 13 was confirmed by PCR and Southern blot analysis, and transcripts containing exons 1-6 were also undetectable by RT-PCR of liver mRNA (Figure 1, B and C).

Intercross of Adamts $13^{+/-}$mice yielded the expected Mendelian distribution of Adamts13 genotypes (Table 1), demonstrating that ADAMTS13 is not required for murine embryonic develop- ment or perinatal survival. Although pregnancy has been associated with the onset of TTP in humans (1), both male and female Adamts $13^{-/-}$mice are fertile, and female Adamts $13^{-/-}$mice experienced uncomplicated pregnancies with grossly normal litter sizes. Survival of Adamts13 $13^{+/}$, Adamts $13^{+/-}$, and Adamts $13^{-/-}$mice followed for more than 2 years was also identical (Figure 2A).

We also generated a second independently targeted ADAMTS13-deficient mouse line with exon 3 of Adamts 13 deleted (Adamts13 ${ }^{\Delta e x 3}$ [see Supplemental Figure 1; supplemental material available online with this article; doi:10.1172/JCI26007DS1]). Intercross of Adamts $13^{\text {dex3+/- }}$ mice also resulted in the expected Mendelian distribution of progeny, and initial analyses indicate that these mice possess a phenotype indistinguishable from that of the mice deficient in exons 1-6 of Adamts 13, with which all subsequent experiments were performed.

ADAMTS13-deficient mice demonstrate loss of $v$ WF-cleaving activity with an unchanged $v W F$ multimer distribution. In humans, ADAMTS13 regulates the size of $\mathrm{vWF}$ multimers in the circulation by cleaving $\mathrm{VWF}$ subunits between tyrosine 1605 and methionine 1606 (14). Cleavage of murine vWF at this same site by murine ADAMTS13 has recently been demonstrated in vitro (15). Absence of ADAMTS13 activity in familial or acquired TTP results in the appearance of UL-vWF (8, 16-18). Despite the complete loss of vWF-cleaving activity (Figure 3, $A$ and $B)$, no difference was evident among the vWF multimer patterns of Adamts $13^{+/+}$ and Adamts $13^{-/-}$mice (Figure 3C) on a mixed-strain C57BL/6J and 129X1/SvJ genetic background (Adamts13 $\left.3^{B / 129}\right)$. Furthermore, vWF multimers from both genotypes appeared similar in size to those from patients with familial TTP (data not shown). Thus, mice of this genetic background appear to exhibit UL-vWF regardless of ADAMTS13 expression status.

In contrast to the striking thrombotic microangiopathy seen in humans with TTP, peripheral blood smears prepared from healthy Adamts $13^{B / 129-1-}$ mice were indistinguishable from those of their wild-type littermates (Figure 4, A and B) without evidence of schis-

\section{Table 1}

Mendelian distribution of Adamts $13^{++}$, Adamts $13^{+/-}$, and Adamts13-- progeny

\begin{tabular}{lcccc} 
Genotype & Expected & Adamts13B/129 & Adamts13/CN1 & Adamts13B/CN2 \\
$+/+$ & $25 \%$ & $113(23 \%)$ & $64(25 \%)$ & $40(25 \%)$ \\
$+/-$ & $50 \%$ & $258(53 \%)$ & $131(51 \%)$ & $79(49 \%)$ \\
$-/-$ & $25 \%$ & $115(24 \%)$ & $60(24 \%)$ & $42(26 \%)$ \\
Total & & 486 & 255 & 161 \\
\hline
\end{tabular}



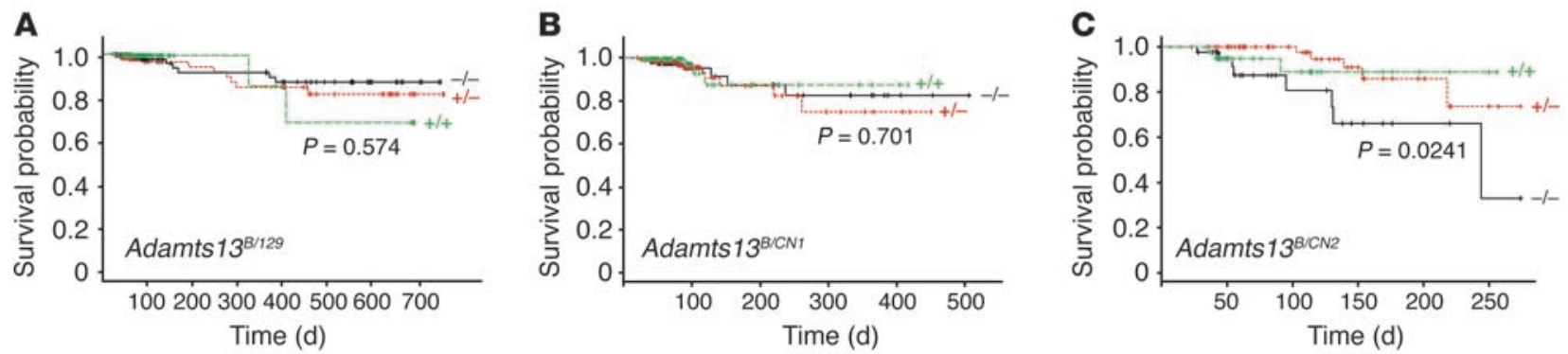

Figure 2

Kaplan-Meier survival plot for ADAMTS13-deficient mice and littermate controls. (A) Adamts13 B/129+/+, Adamts13 ${ }^{B / 129+/-}$, and Adamts13 $1 / 129-/-$ mice $\left(n=579\right.$ mice). (B) Adamts $13^{B / C N 1+/+}$, Adamts $13^{B / C N 1+/}$, and Adamts13 $3^{B / C N 1-/-}$ mice $\left(n=658\right.$ mice). (C) Adamts $13^{B / C N 2+/+}$, Adamts $13^{B / C N 2+/-}$, and Adamts $13^{B / C N 2-/-}$ mice ( $n=169$ mice). Probability of survival was calculated and plotted using the R Statistical Computing Package (39).

tocytes, rbc fragments, or thrombocytopenia. Automated peripheral blood analysis revealed no significant difference in $\mathrm{rbc}, \mathrm{wbc}$, or platelets (Table 2). Finally, histopathological survey revealed that tissues prepared from Adamts $13^{B / 129-/-}$ mice were indistinguishable from their wild-type littermates controls (Figure 4, C-H). Specifically, the typical pink-staining "hyaline thrombi" seen in affected organs from TTP patients was not observed in Adamts $13^{B / 129-/-}$ mice, nor were any other vascular or developmental abnormalities detected.
These results demonstrate that ADAMTS13 deficiency is not sufficient for the development of frequent spontaneous TTP in Adamts $13^{B / 129-/-}$ mice. In contrast, at least half of humans with familial TTP present at birth or in the neonatal period (10). Hemostatic and other differences between humans and mice could account for the disparate phenotypes of these 2 species. For example, mice could possess an alternate protease whose function partially compensates for ADAMTS13 deficiency.
A

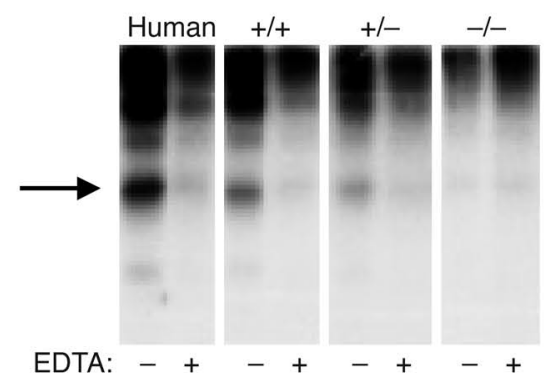

B

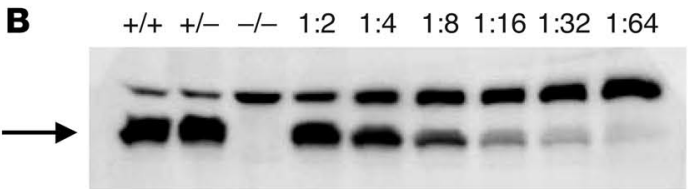

\section{C}

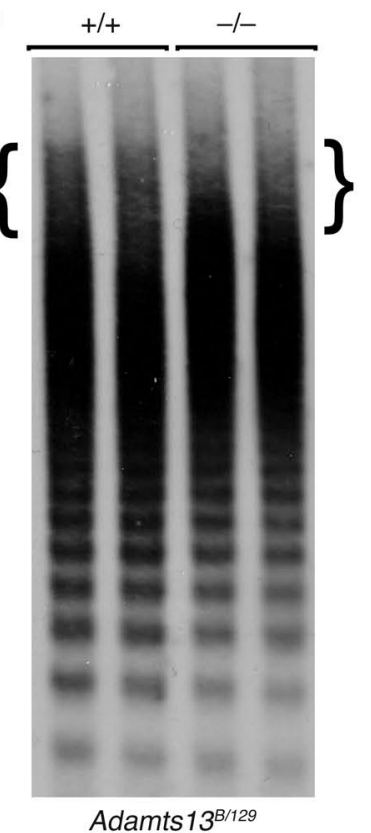

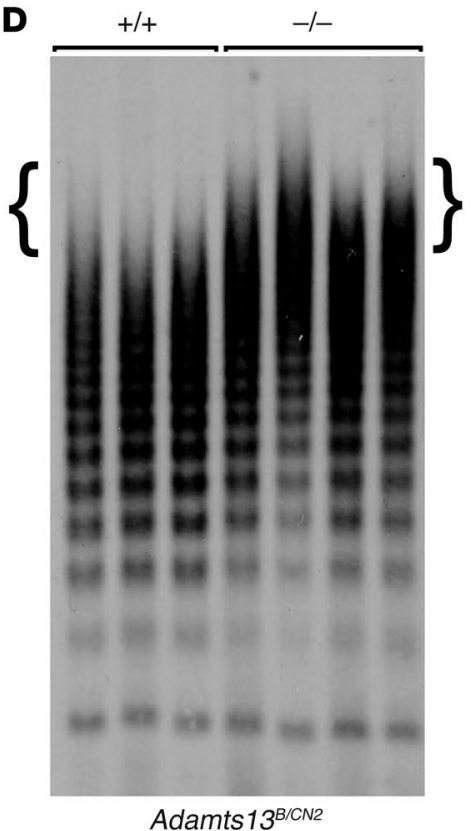

Figure 3

Plasma vWF-cleaving activity and vWF multimer size distribution for ADAMTS13-deficient mice and littermate controls. (A) vWF-cleaving activity in plasma from Adamts13 $1 / 129+/+$, Adamts $13^{B / 129+/-}$, and Adamts13B/129-/- mice measured using purified human full-length vWF as a substrate. Activity was determined by analysis of the specific vWF-cleavage product indicated by the arrow, and comparison to the pattern in the control lane with ADAMTS13 activity completed inhibited by EDTA, as indicated. Specific ADAMTS13 activity was seen in plasma from Adamts13B/129+/+ and Adamts13 B/129+/- mice but not Adamts13B/129-/- mice. (B) vWF-cleaving activity in plasma from Adamts13B/129+/+, Adamts $13^{B / 129+/-}$, and Adamts $13^{B / 129-/-}$ mice determined using recombinant murine GST/vWF A2 domain as a substrate, which contains the previously identified ADAMTS13 cleavage site. Activity was demonstrated by appearance of the expected cleavage product indicated by the arrow. Specific ADAMTS13 activity was seen in plasma from Adamts $13^{B / 129+/+}$ and Adamts $13^{B / 129+/-}$ mice but not Adamts $13^{B / 129-/-}$ mice. Serial dilution of Adamts $13^{\mathrm{B} / 129+/+}$ plasma demonstrated sensitivity to less than $1.5 \%$ of control plasma activity. (C) The vWF multimer distribution in plasma from Adamts $13^{B / 129+/+}$ and Adamts $13^{B / 129-/-}$ mice. (D) The vWF multimer distribution in plasma from Adamts $13^{B / C N 2+/+}$ and Adamts $13^{B / C N 2-/-}$ mice. The approximate range of UL-vWF is indicated by the brackets. 


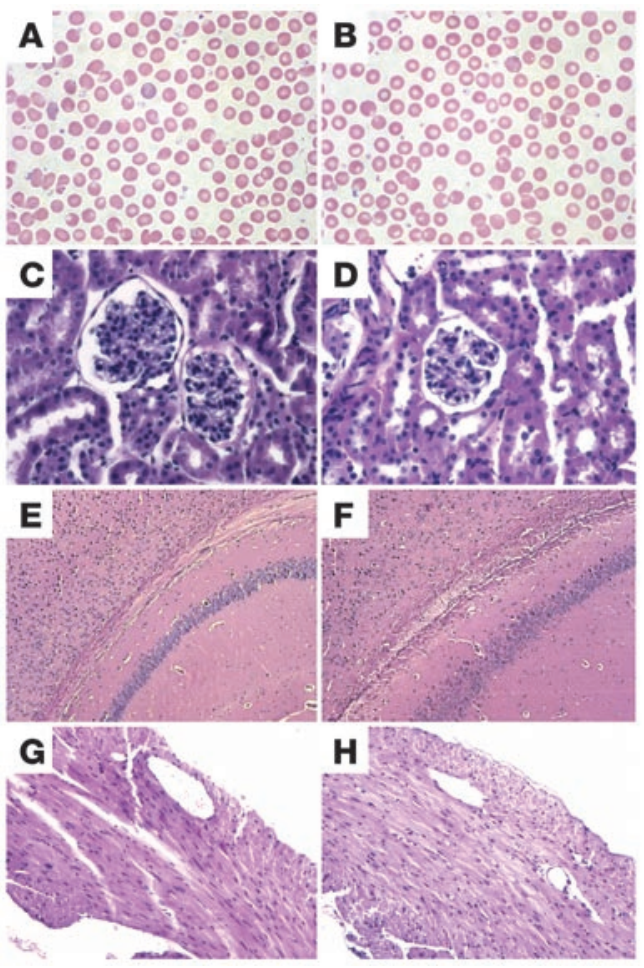

Introduction of the CASA/Rk genetic background alters the $v$ WF multimer distribution, decreases survival, and results in spontaneous TTP. To examine the effect of genetic background on the ADAMTS13 deficiency phenotype, we crossed the Adamts 13 mutation onto the CASA/Rk strain. We chose CASA/Rk because of its relatively large genetic distance from C57BL/6J and 129X1/SvJ and our previous observation that mice of this strain exhibit vWF levels approximately 5- to 10-fold higher than C57BL/6J mice (19). We reasoned that in the setting of ADAMTS13 deficiency, an increase in plasma vWF level may lead to increased susceptibility to TTP. After 1 (Adamts13 $3^{B / C N 1}$ ) and $2\left(\right.$ Adamts $\left.13^{B / C N 2}\right)$ generations of backcross to CASA/Rk, mean plasma vWF level increased by $40 \%$ and $50 \%$, respectively (Figure 5A). This increase in vWF did not affect viability, as the numbers of Adamts $13^{\mathrm{B} / \mathrm{CN} 1-/-}$ and Adamts $13^{\mathrm{B} /}$ $\mathrm{CN} 2-/-$ mice observed at weaning were consistent with the expected Mendelian distributions (Table 1).

\section{Figure 4}

Lack of TTP pathology in Adamts13 B/129-/- mice. (A and B) Peripheral blood smears from Adamts 13B/129+/+ $(\mathbf{A})$ and Adamts13B/129-/(B) mice appear identical, without evidence of schistocytes, rbc fragments, thrombocytopenia, or nucleated rbc. (C-H) H\&Estained tissue sections from Adamts $13^{B / 129+/+}(\mathbf{C}, \mathbf{E}$, and $\mathbf{G})$ and Adamts $13^{B / 129-/-}(\mathbf{D}, \mathbf{F}$, and $\mathbf{H})$ are indistinguishable, without evidence of the pink-staining "hyaline thrombi" typically seen in affected organs from humans with TTP. Representative sections are shown from kidney ( $\mathbf{C}$ and $\mathbf{D})$ ), brain ( $\mathbf{E}$ and $\mathbf{F})$, and heart ( $\mathbf{G}$ and $\mathbf{H})$. Magnification, $\times 1,000(\mathbf{A}$ and $\mathbf{B}) ; \times 400(\mathbf{C}$ and $\mathbf{D}) ; \times 100(\mathbf{E}$ and $\mathbf{F}) ;$ and $\times 200(\mathbf{G}$ and $\mathbf{H})$.

The plasma vWF multimer distribution in plasma from Adamts $13^{B / C N 2}$ mice is shown in Figure 3D. In contrast to Adamts $13^{B / 129+/+}$ mice (Figure 3C), Adamts $13^{B / C N 2+/+}$ mice exhibited a loss of UL-vWF, with an appearance similar to normal humans. In addition, vWF multimers in Adamts $13^{B / C N 2-/-}$ mice differed markedly from their Adamts $13^{B / C N 2+/+}$ littermates, with the clear appearance of UL-vWF similar to the pattern observed in humans with familial TTP. Peripheral blood analysis demonstrated a significant decrease in average platelet count in both Adamts $13^{B / C N 1-/-}$ and Adamts $13^{B / C N 2-/-}$ mice compared with wild-type and heterozygous littermate controls and with Adamts13B/129-/mice (Figure $5 \mathrm{~B}$ ). In addition, 2 of 48 Adamts $13^{B / C N 1-/-}$ mice (4\%) and 5 of 24 Adamts $13^{B / C N 2-/-}$ mice (21\%) were severely thrombocytopenic at baseline (vs. $0 \%$ of littermate controls). These data suggest accelerated platelet consumption in the Adamts $13^{B / C N 1-/-}$ and Adamts $13^{B / C N 2-/-}$ mice as a result of ADAMTS13 deficiency. Adamts $13^{B / C N 2-/-}$ mice also exhibited significantly decreased survival compared with Adamts $13^{B / C N 2+/+}$ and Adamts $13^{B / C N 2+/-}$ littermate controls (Figure 2C), suggesting that the CASA/Rk genetic background introduced enhanced susceptibility to TTP. Consistent with this notion, sporadic Adamts $13^{B / C N 2-/-}$ mice were observed to spontaneously develop severe microangiopathic changes in the peripheral blood, along with widespread vWF-rich and fibrin-poor hyaline thrombi in the small vessels of multiple organs (Figure 6), strikingly similar to the findings in humans with TTP. Though observed in rare individual mice in the Adamts $13^{B / 129}$, Adamts $13^{B / C N 1}$, and Adamts $13^{B / C N 2}$ genetic backgrounds, this pattern appeared more frequent in the latter (not statistically significant) and was typically associated with preceding baseline thrombocytopenia.

\section{Table 2}

Hematologic data of Adamts13 ${ }^{B / 129}$, Adamts13/CN1 and Adamts13B/CN2 mice

\begin{tabular}{|c|c|c|c|c|c|c|c|}
\hline & & wbc $\left(\times 10^{3}\right.$ cells $\left./ \mu \mathrm{l}\right)$ & HGB (g/dl) & НСТ (\%) & PLT $\left(\times 10^{3}\right.$ cells $\left./ \mu \mathrm{l}\right)$ & MCV (fl) & RDW (\%) \\
\hline Adamts13 $3 / 129$ & $\begin{array}{l}+/+ \\
+/- \\
-1-\end{array}$ & $\begin{array}{r}9.5 \pm 2.6 \\
10.0 \pm 2.3 \\
10.7 \pm 2.4\end{array}$ & $\begin{array}{l}16 \pm 1.4 \\
17 \pm 1.3 \\
16 \pm 0.8\end{array}$ & $\begin{array}{l}57 \pm 2.7 \\
59 \pm 3.0 \\
57 \pm 2.5\end{array}$ & $\begin{array}{l}1,460 \pm 202 \\
1,360 \pm 167 \\
1,350 \pm 252\end{array}$ & $\begin{array}{l}54.0 \pm 1.5 \\
54.5 \pm 1.0 \\
55.5 \pm 1.4\end{array}$ & $\begin{array}{l}11.9 \pm 0.6 \\
11.5 \pm 0.8 \\
11.6 \pm 0.7\end{array}$ \\
\hline Adamts13 $3 / C N 1$ & $\begin{array}{l}+/+ \\
+/- \\
-1-\end{array}$ & $\begin{array}{r}10.3 \pm 4.2 \\
8.4 \pm 3.4 \\
10.5 \pm 3.5\end{array}$ & $\begin{array}{l}17 \pm 1.0 \\
17 \pm 0.7 \\
17 \pm 0.8\end{array}$ & $\begin{array}{l}61 \pm 3.3 \\
61 \pm 1.9 \\
59 \pm 2.5\end{array}$ & $\begin{array}{l}1,270 \pm 211 \\
1,370 \pm 155 \\
1,193 \pm 274\end{array}$ & $\begin{array}{l}56.6 \pm 2.7 \\
56.1 \pm 2.8 \\
55.9 \pm 2.4\end{array}$ & $\begin{array}{l}13.1 \pm 1.8 \\
12.3 \pm 1.3 \\
12.7 \pm 1.2\end{array}$ \\
\hline Adamts13 $3 / C N 2$ & $\begin{array}{l}+/+ \\
+/- \\
-1-\end{array}$ & $\begin{array}{r}11.1 \pm 4.5 \\
9.2 \pm 2.6 \\
9.0 \pm 3.5\end{array}$ & $\begin{array}{l}17 \pm 1.2 \\
16 \pm 1.2 \\
17 \pm 1.0\end{array}$ & $\begin{array}{l}59 \pm 3.6 \\
59 \pm 2.8 \\
60 \pm 2.9\end{array}$ & $\begin{array}{r}1,170 \pm 152 \\
1,260 \pm 294 \\
954 \pm 417\end{array}$ & $\begin{array}{l}57.2 \pm 2.3 \\
56.2 \pm 2.7 \\
58.3 \pm 2.8\end{array}$ & $\begin{array}{l}14.6 \pm 2.8 \\
15.5 \pm 1.7 \\
13.9 \pm 1.8\end{array}$ \\
\hline
\end{tabular}

Values are mean \pm SD. HCT, hematocrit; HGB, hemoglobin; MCV, mean corpuscular volume; PLT, platelet; RDW, red cell distibution width. 


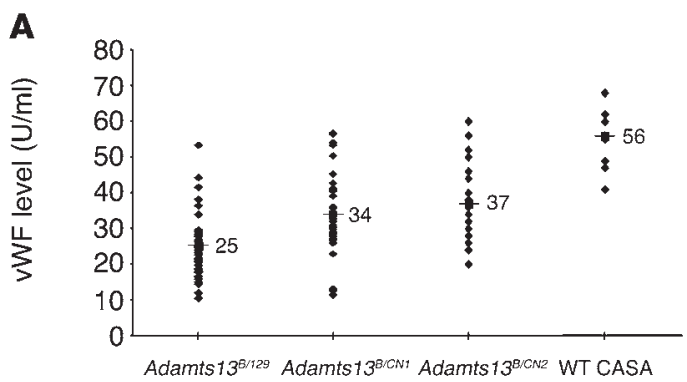

:

ADAMTS13 deficiency prolongs $v$ WF-mediated platelet-endothelial interactions in vivo. Following release of Weibel-Palade bodies, platelets transiently adhere to the stimulated murine endothelium in vivo, in a glycoprotein Ib- (on platelets) and vWF- (on the endothelium) dependent manner $(20,21)$. ADAMTS13 has been shown to cleave newly released UL-vWF multimers that are present on the surface of endothelial cells following stimulation in vitro (22). These observations support the hypothesis that ADAMTS13 regulates vWF function by cleaving newly released UL-vWF from the surface of endothelial cells, thus reducing platelet adhesion and spontaneous aggregation that would ultimately lead to thrombosis and development of TTP.

We investigated platelet-endothelial interactions in the Adamts $13^{B / 129+/+}$ and Adamts $13^{B / 129-/-}$ mice and in Adamts $13^{B / C N 1+/+}$ and Adamts13 $3^{B / C N 1-/-}$ mice (Figure 7 and supplemental videos). At baseline, similar platelet adhesion was seen in Adamts13 $3^{+/+}$ and Adamts $13^{-/-}$mice of both genetic backgrounds. Following superfusion of the calcium ionophore A23187 (which stimulates UL-vWF release from endothelial cells; ref. 5), platelet adhesion rapidly increased in all mice (Figure 7, A and B). Subsequently, wild-type mice of both genetic backgrounds returned to baseline by approximately 5 minutes. In contrast, the ADAMTS13-deficient mice showed significantly prolonged adhesion, remaining above baseline through 8 and 15 minutes in the Adamts $13^{B / 129-/-}$ and Adamts $13^{B / C N 1-/-}$ mice, respectively. Furthermore, in 3 of the 7 Adamts $13^{B / C N 1-/-}$ mice studied, platelet adhesion continued throughout the entire 35-minute observation period. Adhesion was absent in stimulated $V w f^{-/}$venules, confirming that this process is vWF dependent (Figure 7B). In all experiments, long-lived strings of platelets varying from 20 to $60 \mu \mathrm{m}$ were observed in Adamts 13 $3 / 129-/-$ mice (Figure $7 C$ ). These strings appeared to be attached at one end and "waved" with the flow of blood in the vessel. Even longer strings were observed in the Adamts $13^{\mathrm{B} / \mathrm{CN1-/-}}$ mice. Smaller and shorter-lived (less than 1 second) strings were occasionally seen in wild-type mice of both genetic backgrounds. These results provide what we believe to be the first

\section{Figure 5}

Baseline VWF level and platelet counts of mice used in this study. (A) VWF levels in plasma from Adamts13B/129, Adamts13B/CN1, Adamts 13B/CN2, and wild-type CASA/Rk mice. vWF levels were measured by ELISA and expressed in units/milliliter, with the vWF level in pooled C57BL/6J plasma set to $10 \mathrm{U} / \mathrm{ml}$ as a standard. The mean values for each mouse strain and genotype combination are indicated by horizontal bars. (B) Baseline platelet counts in healthy-appearing Adamts 13 $3^{B / 129}$, Adamts $13^{B / C N 1}$, and Adamts $13^{B / C N 2}$ mice displayed as ADAMTS13 positive (+/+ and +/-) and ADAMTS13 negative (-/-). The mean values for each group are indicated by horizontal bars. Baseline thrombocytopenia was observed in 0 of 33 Adamts $13^{B / 129-/-}$ mice $(0 \%)$, 2 of 48 Adamts $13^{B / C N 1-I-}$ mice (4\%), and 5 of 24 Adamts $13^{B / C N 2-I-}$ mice $(21 \%)$. If more than 1 baseline platelet measurement for an individual mouse was available, the lowest value was used. Statistical significance was assessed by Student's $t$ test.

direct evidence that ADAMTS13 regulates $\mathrm{VWF}$-mediated platelet adhesion in vivo.

Shigatoxin triggers TTP in Adamts $13^{\mathrm{B} / \mathrm{CN} 2-/-}$ mice. The human disease hemolytic uremic syndrome (HUS) exhibits clinical and pathologic findings very similar to TTP, leading some investigators to group TTP and HUS into a single category, TTP/HUS $(1,23)$. Acute HUS is caused by infection with strains of E. coli and Shigella dysenteriae that secrete shigatoxin (Stx), a substance toxic to endothelial cells (24). Endothelial injury has also been hypothesized to play a role in TTP pathogenesis and could represent a common mechanistic link between TTP and HUS (1).

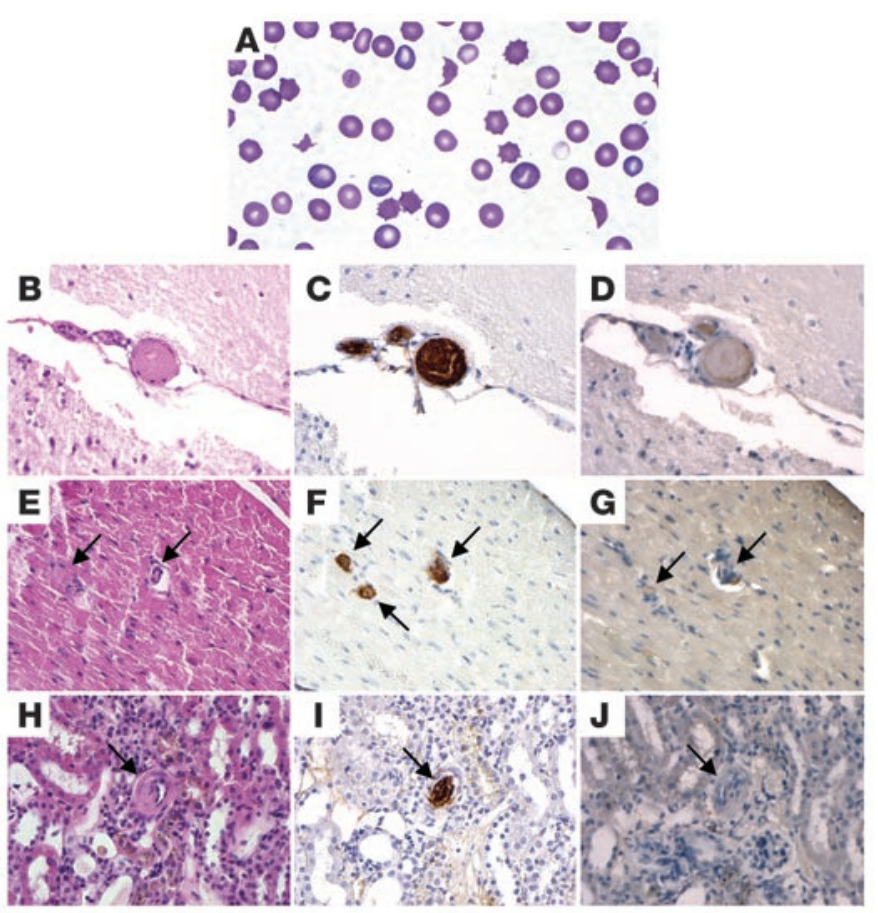

\section{Figure 6}

Spontaneous TTP in Adamts13B/CN2-/- mice. (A) Peripheral blood smear showing thrombocytopenia, schistocytes, and fragmented rbc. (B-J) Tissue sections showing vWF-rich and fibrin-poor thrombi in small blood vessels from brain $(\mathbf{B}-\mathbf{D})$, heart $(\mathbf{E}-\mathbf{G})$, and kidney $(\mathbf{H}-\mathbf{J})$. Sections were stained with $\mathrm{H} \& \mathrm{E}(\mathbf{B}, \mathbf{E}$, and $\mathbf{H})$, anti-vWF (C, F, and I), or anti-fibrinogen (D, G, and $\mathbf{J})$. Difficult-to-visualize thrombi are indicated with arrows. Magnification, $\times 1,000(\mathbf{A})$; and $\times 200(\mathbf{B}-\mathbf{J})$. 

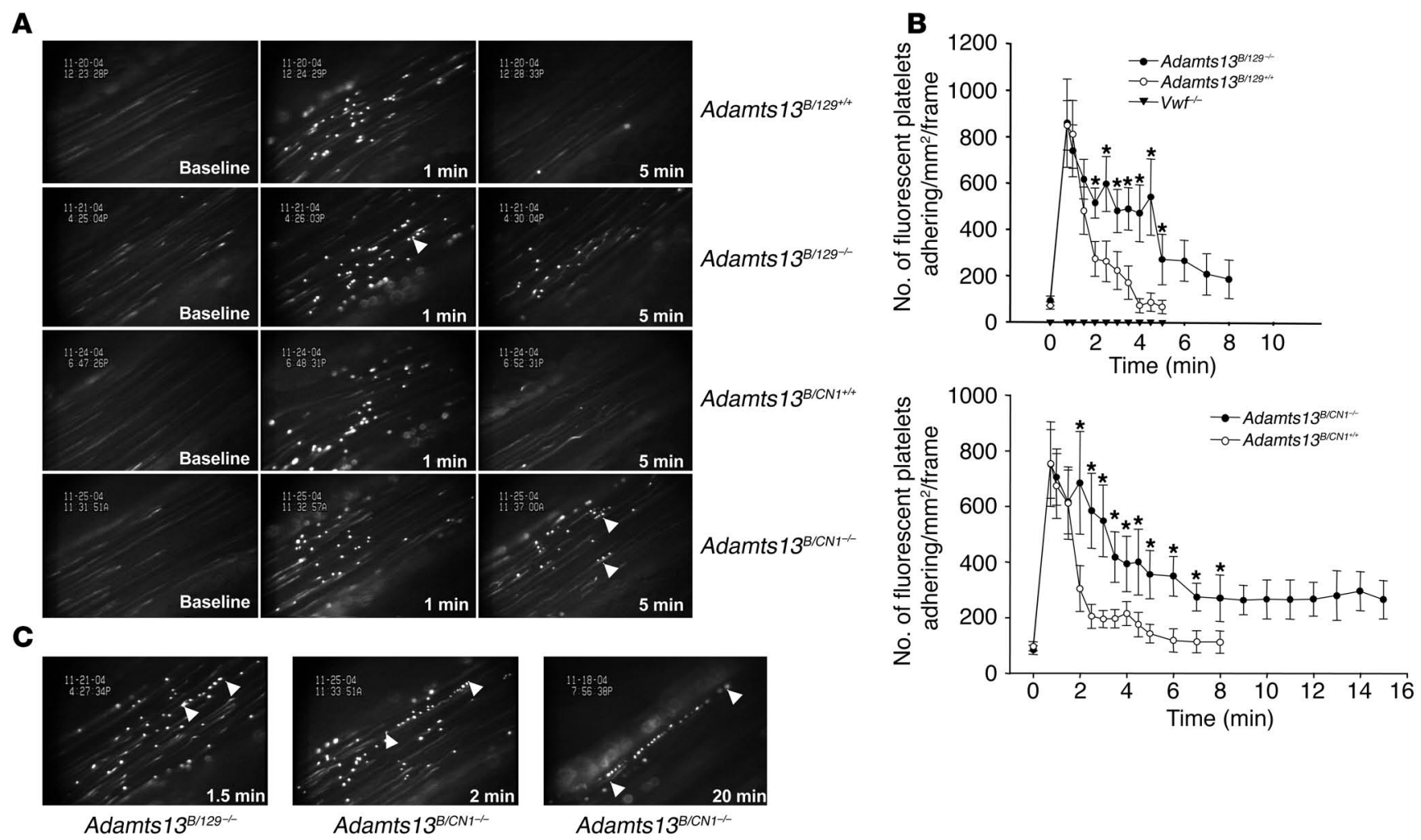

\section{Figure 7}

ADAMTS13 deficiency prolongs VWF-mediated platelet-endothelial cell interactions in vivo. (A) Fluorescently labeled platelets began to adhere to the endothelium of mesenteric venules within 30-45 seconds after superfusion of calcium ionophore A23187. The adhesion was short lived in +/+ mice, whereas it was longer lived in ADAMTS13-deficient mice. Arrowheads indicate attached strings of platelets at least $20 \mu \mathrm{m}$ in length. The insets indicate time after superfusion of A23187. (B) Quantification of fluorescent platelets sticking and/or translocating on vWF in A23187activated venules. Adhesion of platelets to the vessel wall reached a peak between 45 seconds and 1 minute following superfusion of A23187 and progressively decreased with time. This process was absent in $V w f^{-1-}$ mice. Significantly more platelet adhesion was observed after 2 minutes and continued longer in the Adamts $13^{B / 129-/-}$ and Adamts13//CN1-/- mice compared with littermate +/+ controls. In 3 of 8 Adamts $13^{B / 129-/-}$ mice, platelet adhesion continued through 16 minutes. Similarly, in 3 of 7 Adamts $13^{B / C N 1-l-}$ mice, platelet adhesion continued through 35 minutes. ${ }^{\star} P<0.05$. (C) Fluorescent platelets aligned with a "beads-on-a-string" appearance on vWF in activated mesenteric venules. Very long strings up to $180 \mu \mathrm{m}$ were observed. Video recordings of these experiments are provided in the supplemental material.

Adamts13 $3^{B / 129+/+}$ and Adamts13 $3^{B / 129-/-}$ mice injected with $200-250 \mathrm{pg} / \mathrm{g}$ of Stx i.v. exhibited no consistent change in rbc or platelet counts (Figure 8, A-D), with similar mortality in both groups $(\sim 20 \%)$. However, striking differences were observed between ADAMTS13deficient and control mice in the Adamts13 ${ }^{B / C N 2}$ genetic background (Figure 8, E-H). At 125 pg/g Stx, 6 of 13 Adamts13B/CN2-/mice had died by day 10 , compared with 1 of 9 control Adamts $13^{B / C N 2+/+}$ mice $(P<0.01)$. Stx also induced profound thrombocytopenia in the Adamts $13^{B / C N 2-/-}$ mice, with 12 of 13 animals demonstrating an at least $50 \%$ decrease in platelet count, and 8 of 13 mice showing a greater than $80 \%$ reduction (Figure $8 \mathrm{G}$ ), compared with only modest decreases in Adamts $13^{B / C N 2+/+}$ controls (Figure 8E). Five of 13 Adamts $13^{B / C N 2-/-}$ mice (Figure $8 \mathrm{H}$ ) also developed severe anemia compared with 0 of 9 controls (Figure 8F). In addition, examination of peripheral blood and tissue histology from Adamts $13^{B / C N 2-/-}$ mice revealed the classic TTP findings of microangiopathic hemolytic anemia and widespread vWF-rich and fibrin-poor hyaline thrombi in the small vessels of multiple organs (Figure 9). These results demonstrate that Stx infusion into Adamts $13^{B / C N 2-/-}$ mice results in a syndrome closely resembling human TTP.
Plasma $v$ WF level is not a risk factor for TTP in mice. Plasma vWF levels in the Mus casteneous strain CASA/Rk are known to be 5- to 10 -fold higher than in the more commonly studied Mus musculus strain C57BL/6J (19). Could these elevated vWF levels account for the increased mortality and baseline thrombocytopenia as well as the enhanced susceptibility to Stx-induced TTP observed in Adamts $13^{B / C N 2-/-}$ mice compared with Adamts $13^{B / 129-/-}$ mice? As human plasma vWF levels are also highly variable (25), could genetic and other factors modifying $v W F$ levels also serve as key risk factors for TTP in humans? Surprisingly, we observed no correlation between elevated plasma vWF level and mortality (Figure 10A), baseline platelet count (Figure 10B), or degree of thrombocytopenia (Figure 10C). These data demonstrate that elevated plasma vWF level is not a TTP risk factor in mice and suggest that a genetic modifying factor (or factors) other than $\mathrm{VWF}$ level introduced by the CASA/Rk cross plays a key role in TTP pathogenesis.

\section{Discussion}

Our results demonstrate that complete ADAMTS13 deficiency is not lethal in mice and in fact is surprisingly well tolerated on some genetic backgrounds. These observations may reflect the 


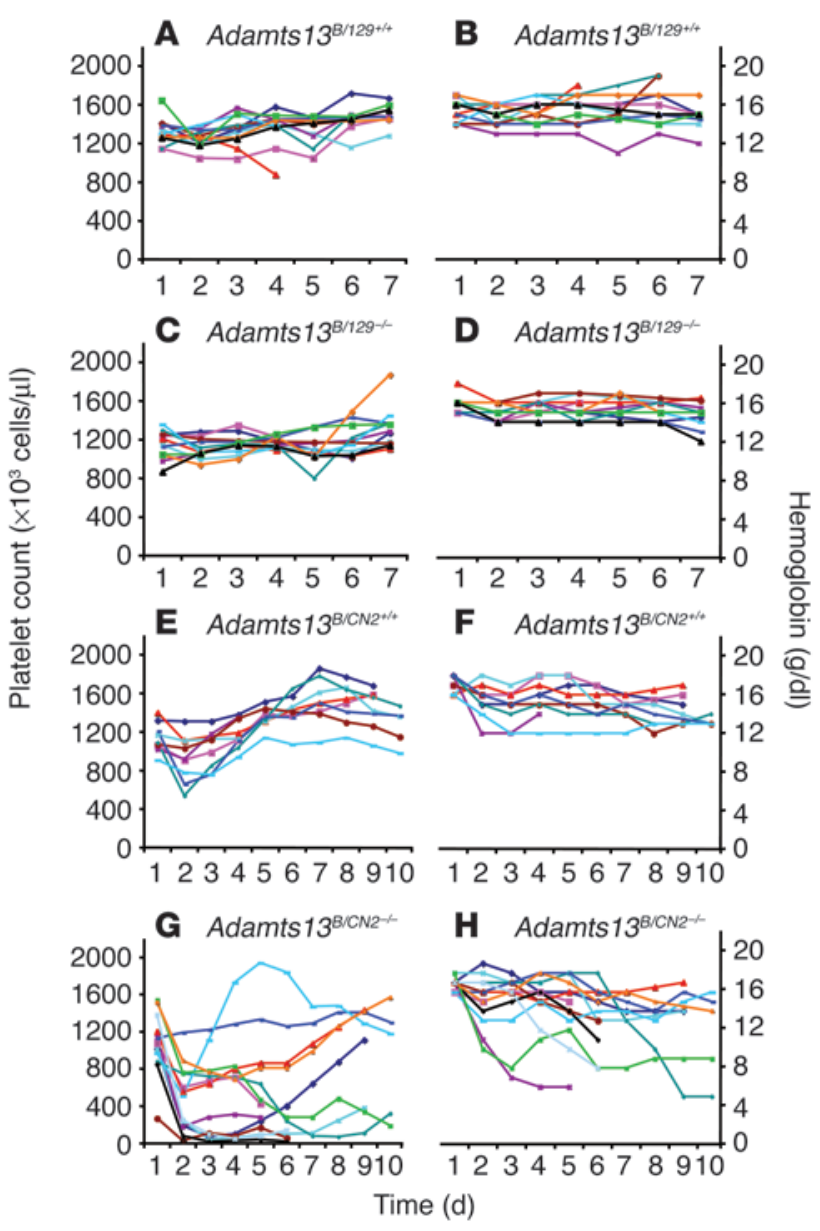

situation in humans, where many familial TTP cases are not diagnosed until early adulthood, with rare individuals carrying ADAMTS13 disease-causing mutations reported to remain free of TTP through the third decade of life (10). Taken together, these observations in humans and mice suggest that loss of ADAMTS13 activity, with the associated increase in circulating UL-vWF multimers, may be necessary, but not sufficient, for the induction of clinical TTP and imply the existence of other key genetic modifying factors and/or environmental triggers.

Of note, C57BL/6J mice primarily express a form of ADAMTS13 truncated after the sixth thrombospondin type-1 motif (termed ADAMTS13S), resulting from insertion of a retrovirus-like element into the Adamts13 gene (26). Among the mice used in our study, the wild-type $(+)$ allele of all B/129 mice was always C57BL/6J derived and therefore truncated; and the wild-type allele of all B/CN1 and $\mathrm{B} / \mathrm{CN} 2$ mice was always CASA/Rk derived and therefore nontruncated (data not shown). ADAMTS13S lacks the 2 C-terminal CUB domains but retains grossly normal vWF-cleaving activity in vitro. However, several missense and truncation mutations distal to TSP1-6 have been found in human familial TTP patients, suggesting that these sequences may be required for full ADAMTS13 function in vivo. Similarly, truncated C57BL/6J ADAMTS13 may also be hypomorphic in vivo, potentially accounting for the UL-vWF multimers observed in mice homozygous for this allele. The absence of thrombosis or other manifestations of TTP in wild-type C57BL/6J mice suggests that these mice may harbor 1 or more

\section{Figure 8}

Stx challenge of Adamts $13^{B / 129}$ and Adamts $13^{B / C N 2}$ mice. Mice were injected via the tail vein with Stx (200-250 pg/g body weight for Adamts $13^{B / 129}$ mice [A-D] and $125 \mathrm{pg} / \mathrm{g}$ for Adamts $13^{B / C N 2}$ mice $[\mathrm{E}-\mathrm{H}]$ ), and survival was monitored for 10 days. Blood from the retroorbital plexus was obtained daily for automated analysis and preparation of smears. Daily platelet counts (A, C, E, and $\mathbf{G})$ and hemoglobin values $(\mathbf{B}, \mathbf{D}, \mathbf{F}$, and $\mathbf{H})$ are shown.

"balancing mutations" selected during strain derivation $(27,28)$, compensating for the relative ADAMTS13 deficiency. Loss of these balancing mutation(s) with the genetic cross onto the CASA/Rk strain might account for the emergence of the more overt TTP phenotype seen in the Adamts $13^{B / C N 2-/-}$ mice.

Interestingly, a common ADAMTS13 variant (P475S) recently was identified in the Japanese population that demonstrates negligible vWF-cleaving activity in vitro (12). With an allele frequency of $5.1 \%$, approximately $10 \%$ of the Japanese population may be heterozygous for P475S (resulting in ADAMTS13 activity of $\sim 50 \%$ ), with up to $1 \%$ possessing severely reduced ADAMTS13 activity secondary to $\mathrm{P} 475 \mathrm{~S}$ homozygosity. However, the frequency of TTP among the Japanese is not reported to be higher than in other populations (29), suggesting sufficient residual activity from the P475S allele or the influence of other genetic or environmental factors. These observations of hypomorphic ADAMTS13 alleles in both humans and mice suggest the possibility that moderately reduced ADAMTS13 activity may be underbalancing selection, similar to hemoglobin mutations in sickle cell anemia and $\alpha$-thalassemia $(30,31)$ and cystic fibrosis $(32,33)$.

The high degree of population variability for plasma vWF levels in humans and mice, together with its function as the only known substrate for ADAMTS13, suggested genetic factors controlling vWF level as leading candidates for modifiers of TTP susceptibility. Indeed, the $25-30 \%$ reduction in plasma vWF seen in individuals with blood type $\mathrm{O}$ might be expected to confer protection against TTP. Surprisingly, our analyses demonstrated no correlation between elevated plasma vWF level in the mouse and the manifestations of TTP. Though this observation remains to be confirmed in humans, these findings suggest that the critical determinants of TTP susceptibility may lie in other genetic factors, perhaps associated with variations in platelet or vessel wall function. However, we cannot exclude a subtle qualitative difference in vWF not reflected in the antigen level measurement. Future characterization of these murine strain-specific modifiers could provide novel insight into the pathogenesis of TTP and the variability of its manifestations in humans.

TTP and HUS share many features, and our finding of a consistent and striking TTP-like illness induced by Stx preferentially in Adamts13 $13^{B / C N 2-1-}$ mice suggests a mechanistic link between these 2 disorders. However, most cases of TTP and HUS remain clinically and pathologically distinct, likely indicating divergent pathological mechanisms following this disease-initiating event. These data also suggest that Stx, or other similar microbially derived toxins, may be key environmental triggers for TTP. These observations might also explain the frequent association of an infectious prodrome with acute episodes of both acquired and familial TTP $(1,10)$.

Finally, it is important to note that C57BL/6J has become the standard "control" inbred mouse strain for gene targeting experiments, particularly in cardiovascular research (34). Our findings suggest that an endogenous mutation in the C57BL/6J Adamts 13 allele, along 


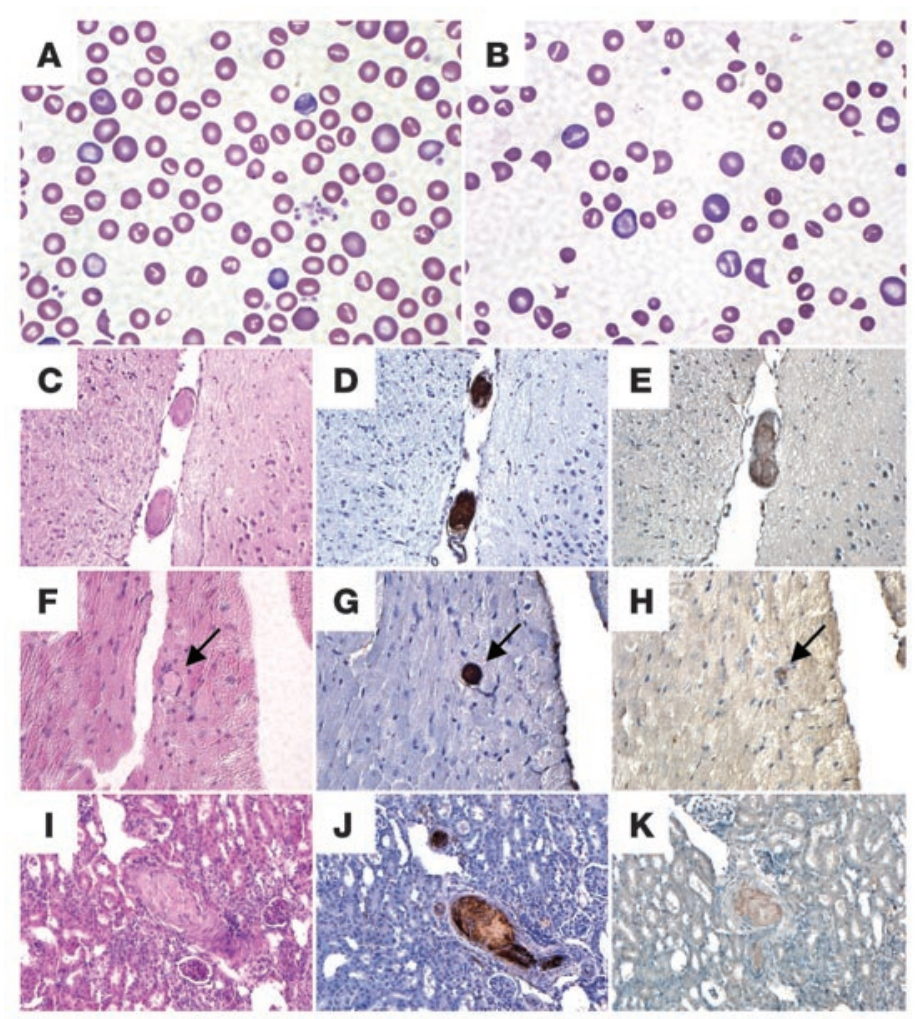

\section{Figure 9}

Pathology consistent with TTP in Adamts $13^{\mathrm{B} / \mathrm{CN} 2-1-}$ mice following Stx challenge. (A) Peripheral blood from a control Adamts 13B/CN2+/+ mouse after Stx challenge. (B) Peripheral blood from an Adamts $13^{B / C N 2-/-}$ mouse shows extensive microangiopathic changes, with numerous schistocytes and rbc fragments. (C-K) In Adamts 13 1 /CN2-I- mice, widespread "hyaline clots" were observed in H\&E-stained sections of brain (C), heart (F), and kidney (I). By immunohistochemistry, these thrombi were intensely positive for vWF (D, G, and $\mathbf{J})$ but only weakly positive for fibrin ( $\mathbf{E}, \mathbf{H}$, and $\mathbf{K})$. Difficult-to-visualize thrombi are indicated with arrows. Magnification, $\times 1,000(\mathbf{A}$ and $\mathbf{B})$; and $\times 200(\mathbf{C}-\mathbf{K})$.

with balancing mutations at one or more additional loci, could complicate the analysis of vascular and hemostatic function in this specific genetic background. This concern may require reinterpretation of a considerable body of previous work addressing atherosclerosis, inflammation, and clot formation in gene-targeted mice.

\section{Methods}

Mouse strains. Mice of strain C57BL/6J and CASA/Rk were obtained from The Jackson Laboratory. Mice were maintained in a specific pathogen-free facility at the University of Michigan. All procedures were approved by the University Care and Use Committee on Animals.

Generation of ADAMTS13-deficient mice. Gene targeting was performed essentially as previously described (35). Briefly, a targeting vector was designed to replace exons 1-6 of murine Adamts 13 with a neomycin-resistance cassette (Figure 1A). With the assistance of the Transgenic Animal Facility at the University of Michigan, this vector was electroporated into murine ES cells from strain 129X1/Sv, and neomycin-resistant clones were selected, verified, expanded, and subsequently injected into C57BL/6J blastocysts, which were then implanted into pseudopregnant C57BL/6J females. High-level male agouti chimeric progeny were bred with C57BL/6J females, and germline transmission of the disrupted Adamts13 allele was verified by Southern blotting of SpeI-digested DNA with cDNA probes both $5^{\prime}$ and $3^{\prime}$ outside of the targeting arms and EcoRI-digested DNA with cDNA probes specific for Adamts13 exons 4-6 and 7-8 (data not shown). Resulting $\mathrm{F}_{1}$ Adamts $13^{+/-}$het-

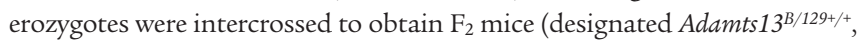
Adamts13 $3^{B / 129+/-}$, and Adamts13 $3^{B / 129-/-}$ ). $\mathrm{F}_{2}$ Adamts $13^{B / 129}$ mice were also backcrossed to wild-type CASA/Rk mice, and the resulting Adamts13 heterozygotes were either intercrossed to obtain Adamts $13^{\mathrm{B} / \mathrm{CN1+/+}}$, Adamts $13^{\mathrm{B} / \mathrm{CN1+/} \text {, }}$ and $A$ damts $13^{B / C N 1-/-}$ mice or were backcrossed again to wild-type CASA/Rk mice. The resulting Adamts 13 heterozygotes from this second backcross were intercrossed to obtain Adamts $13^{\mathrm{B} / \mathrm{CN2+/}}$, Adamts $13^{\mathrm{B} / \mathrm{CN2}+/}$, and Adamts $13^{\mathrm{B} / \mathrm{CN2} 2^{-/}}$ mice. Littermate controls were used for all experiments.
PCR and RT-PCR. The locations of primers used for PCR genotyping are shown in Figure 1A. Tail genomic DNA was extracted and purified as described previously (35). PCR and agarose gel electrophoresis were performed by standard techniques. For RT-PCR, liver mRNA was obtained from Adamts $13^{B / 129^{+/+}}$, Adamts $13^{B / 129+/-}$, and Adamts $13^{B / 129-/-}$ mice using the Oligotex mRNA Midi Kit (QIAGEN). RT-PCR was performed with the SuperScript One-Step RT-PCR kit (Invitrogen Corp.), using oligo-dT for first-strand synthesis, and primers specific to Adamts13 exons 1-6 for the subsequent PCR. The control primers were for murine $\nu W F$.

Analysis of peripheral blood. Blood was collected into 20- $\mu$ l EDTA-coated capillary tubes (Drew Scientific) by retro-orbital bleeding under isoflurane anesthesia. Analysis was performed with a Bayer ADVIA 120 whole blood analyzer (Bayer HealthCare) using the murine C57BL/6 algorithm. Peripheral blood smears were prepared by standard techniques and were fixed and stained with the HEMA 3 system (Fisher Scientific).

Tissue preparation and analysis. Anesthetized mice were exsanguinated by cardiac puncture and subsequently flushed via the left ventricle

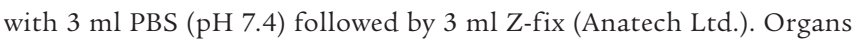
were removed and incubated for 24-48 hours in Z-fix and subsequently embedded in paraffin, sectioned, and stained with H\&E by standard techniques. Immunohistochemistry to identify vWF or fibrin was performed using the ABC method (Vector Laboratories) and anti-vWF A0082 (DakoCytomation) or anti-fibrinogen YNGMFbg7S (Accurate Chemical \& Scientific Corp.) antibodies.

$v$ WF cleavage assays. Whole blood was obtained from the indicated anesthetized mice by cardiac puncture (with $0.1 \mathrm{M}$ sodium citrate as anticoagulant), and plasma was subsequently prepared by centrifugation. Cleavage of glutathione-S-transferase/vWF A2 (GST/vWF A2) was performed as described previously (36). Briefly, $5 \mu \mathrm{l}$ of plasma was incubated with $100 \mathrm{ng}$ of fusion protein in reaction buffer $(5 \mathrm{mM}$ Tris, $10 \mathrm{mM}$ $\mathrm{BaCl}_{2}, 1 \mathrm{mM}$ PMSF, pH 8.0) for 1 hour at $37^{\circ} \mathrm{C}$. Cleavage products were resolved by SDS-14\% PAGE and transferred to nitrocellulose. Proteins 


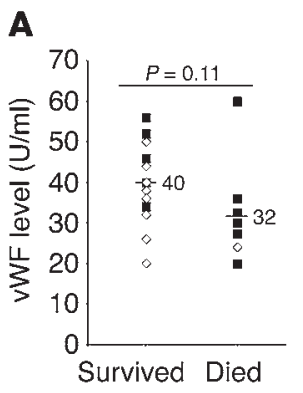

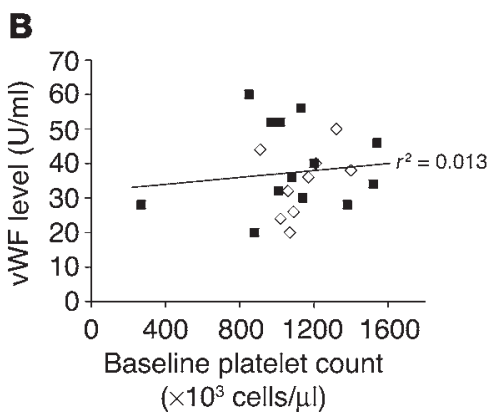

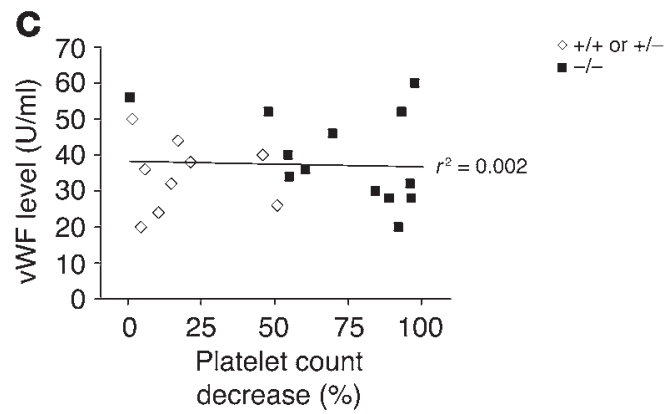

Figure 10

Plasma vWF level is not a risk factor for thrombocytopenia or Stx-induced TTP in Adamts13B/CN2-/- mice. No correlation was observed between plasma vWF level and Stx-induced mortality (A), baseline platelet count (B), Stx-induced thrombocytopenia (C), or Stx-induced anemia (data not shown). The $P$ value in A was calculated by Student's 2-tailed $t$ test, and the $r^{2}$ values in $\mathbf{B}$ and $\mathbf{C}$ are indicated. Open diamonds indicate Adamts $13^{\mathrm{B} / \mathrm{CN} 2+/+}$ and Adamts $13^{\mathrm{B} / \mathrm{CN} 2+/-}$ mice, and filled squares indicate Adamts $13^{\mathrm{B} / \mathrm{CN} 2-\mathrm{I}_{-}}$mice.

were immunoblotted with anti-GST anti-sera (Invitrogen Corp.) followed by a goat anti-rabbit peroxidase-conjugated secondary antibody (Bio-Rad Laboratories). Detection was with ECL (Amersham Biosciences). Cleavage of purified full-length human vWF was performed as described previously (8).

$v$ WF multimer and ELISA analysis. Plasma vWF multimer analysis was performed essentially as described previously (37). Briefly, $0.75 \%$ SeaKem HGT (Cambrex) $11 \times 14 \mathrm{~cm}$ gels were prepared in electrophoresis buffer (40 mM Tris-acetate, pH 7.8, 0.1\% SDS, 1 mM EDTA) and cooled to $4{ }^{\circ} \mathrm{C}$. Whole blood was drawn into $\mathrm{Na}^{+}$-heparin-coated glass capillary tubes, and plasma was separated by centrifugation and diluted 1:10 in sample buffer (0.1 $\mathrm{M} \mathrm{Na}_{2} \mathrm{PO}_{4}$, pH 7.0, 1.0\% SDS). Prior to electrophoresis, $1: 10$ volume loading buffer was added ( $50 \%$ glycerol, $1.0 \%$ bromophenol blue). One to $10 \mu \mathrm{l}$ of diluted plasma was used per well. Gels were electrophoresed at $4^{\circ} \mathrm{C}$ until the bromophenol blue had migrated approximately $10 \mathrm{~cm}$. Proteins were then transferred to nitrocellulose electrophoretically and were subsequently immunoblotted with antivWF antisera A0082 (DakoCytomation), followed by a HRP-conjugated goat anti-rabbit sera (Bio-Rad Laboratories) as the secondary antibody. Detection was with ECL (Amersham Biosciences). Plasma vWF levels were quantified by ELISA as described previously (38), using anti-vWF antisera A0082 as the primary antibody and HRP-conjugated vWF antisera (DakoCytomation) as the secondary. Detection was with 1-step Ultra TMB (Pierce Biotechnology Inc.).

Intravital microscopy. Male and female mice were studied at age 4-8 weeks, at a weight of 14-21 g. Platelets for infusion were isolated from mice of the same genotype at age 4-6 months. The Animal Care and Use Committee of the CBR Institute for Biomedical Research approved all experimental procedures. Blood was harvested from the retro-orbital venous plexus by puncture and collected in 1-ml polypropylene tubes containing $300 \mu \mathrm{l}$ of heparin $(30 \mathrm{U} / \mathrm{ml})$, and platelet-rich plasma (PRP) was obtained by centrifugation. The PRP was transferred to fresh tubes containing $2 \mathrm{ml}$ of prostaglandin $\mathrm{I} 2\left(\mathrm{PGI}_{2}\right)(2 \mathrm{mg} / \mathrm{ml})$ and incubated at $37^{\circ} \mathrm{C}$ for 5 minutes. After centrifugation at $1,500 \mathrm{~g}$, pellets were resuspended in $1 \mathrm{ml}$ modified Tyrode-HEPES buffer $(137 \mathrm{mM} \mathrm{NaCl}, 0.3 \mathrm{mM}$ $\mathrm{Na}_{2} \mathrm{HPO}_{4}, 2 \mathrm{mM} \mathrm{KCl}, 12 \mathrm{mM} \mathrm{NaHCO}_{3}, 5 \mathrm{mM}$ HEPES, $5 \mathrm{mM}$ glucose,

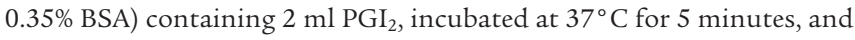
subsequently centrifuged at $1,500 \mathrm{~g}$ for 5 minutes. The washing step was repeated twice to remove $\mathrm{PGI}_{2}$. Platelets were then fluorescently labeled with $0.25 \mathrm{mg} / \mathrm{ml}$ calcein AM (Invitrogen Corp.) for 10 minutes at room temperature. Fluorescent platelets $\left(1.25 \times 10^{9}\right.$ platelets $\left./ \mathrm{kg}\right)$ were infused through the retro-orbital plexus.
Intravital microscopy was as described previously with slight modification (21). Briefly, mice were anesthetized with $2.5 \%$ tribromoethanol $(0.15 \mathrm{ml} / 10 \mathrm{~g})$, and fluorescent platelets were infused after 5 minutes. An incision was made through the abdominal wall to expose the mesentery and mesenteric venules of 200- to 300- $\mu \mathrm{m}$ diameter. One venule per animal was filmed for 3 minutes for baseline determination before A23187 superfusion ( $30 \mu \mathrm{l}$ of a $10 \mu \mathrm{mol} / \mathrm{l}$ solution), and filming continued until after the platelet sticking and rolling decreased to baseline. Adherent fluorescent platelets were quantified over $250-\mu \mathrm{m}$-long and 100 - to $120-\mu \mathrm{m}$-wide venular segments visible on a given frame lasting 0.2 seconds and subsequently translated to the number of fluorescent platelets adhering $/ \mathrm{mm}^{2}$ / frame. Results are reported as the mean \pm SEM. The statistical significance of the difference between means was assessed by the 2-tailed Student's $t$ test. $P<0.05$ was considered statistically significant.

Stx challenge. Stx-2 (Sigma-Aldrich) was diluted to a final concentration of $25 \mathrm{pg} / \mathrm{\mu l}$ in normal saline. Anesthetized mice were injected i.v. with the indicated dose of Stx. Blood for complete blood count analysis and peripheral blood smears was obtained by retro-orbital bleeding prior to injection and subsequently on a daily basis.

\section{Acknowledgments}

This research was supported by NIH grants R01-HL39693 and P01HL057346 (to D. Ginsburg), R01-HL062136 and R01-HL72876 (to H.-M. Tsai), and NIH Merit Award 41002 (to D.D. Wagner). D.G. Motto is the recipient of an American Society of Hematology Scholar Award; J. Homeister is the recipient of American Heart Association Fellow to Faculty Award 0275023N; K.C. Desch is the recipient of an American Heart Association Postdoctoral Fellowship; and D. Ginsburg in an investigator of the Howard Hughes Medical Institute. We acknowledge the Transgenic Animal Model Core of the University of Michigan's Biomedical Research Core Facilities for assistance with generating the gene-targeted mouse lines used in this study. This core is supported by NIH grants CA46592 and AR20557 and by the Michigan Economic Development Corporation grant 085P1000815.

Received for publication June 20, 2005, and accepted in revised form July 26, 2005.

Address correspondence to: David Ginsburg, University of Michigan, 5028 Life Sciences Institute, 210 Washtenaw Avenue, Ann Arbor, Michigan 48109, USA. Phone: (734) 647-4808; Fax: (734) 936-2888; E-mail: ginsburg@umich.edu. 
1. Moake, J.L. 2002. Thrombotic microangiopathies. N. Engl. J. Med. 347:589-600,

2. Asada, Y., Sumiyoshi, A., Hayashi, T., Suzumiya, J., and Kaketani, K. 1985. Immunohistochemistry of vascular lesion in thrombotic thrombocytopenic purpura, with special reference to factor VIII related antigen. Thromb. Res. 38:469-479.

3. Rock, G.A., et al. 1991. Comparison of plasma exchange with plasma infusion in the treatment of thrombotic thrombocytopenic purpura. N. Engl.J. Med. 325:393-397.

4. Levy, G.G., et al. 2001. Mutations in a member of the ADAMTS gene family cause thrombotic thrombocytopenic purpura. Nature. 413:488-494.

5. Sporn, L.A., Marder, V.J., and Wagner, D.D. 1986. Inducible secretion of large, biologically potent von Willebrand factor multimers. Cell. 46:185-190.

6. Furlan, M., et al. 1997. Deficient activity of von Willebrand factor-cleaving protease in chronic relapsing thrombotic thrombocytopenic purpura. Blood. 89:3097-3103.

7. Furlan, M., et al. 1998. von Willebrand factor-cleaving protease in thrombotic thrombocytopenic purpura and the hemolytic-uremic syndrome. N. Engl. J. Med. 339:1578-1584.

8. Tsai, H.-M., and Lian, E.C.-Y. 1998. Antibodies to von Willebrand factor-cleaving protease in acute thrombotic thrombocytopenic purpura. N. Engl. J. Med. 339:1585-1594

9. Shumak, K.H., Rock, G.A., and Nair, R.C. 1995. Late relapses in patients successfully treated for thrombotic thrombocytopenic purpura. Canadian Apheresis Group. Ann. Intern. Med. 122:569-572.

10. Furlan, M., and Lammle, B. 2001. Aetiology and pathogenesis of thrombotic thrombocytopenic purpura and haemolytic uraemic syndrome: the role of von Willebrand factor-cleaving protease. Best Pract. Res. Clin. Haematol. 14:437-454.

11. Studt, J.D., et al. 2004. Familial acquired thrombotic thrombocytopenic purpura: ADAMTS-13 inhibitory autoantibodies in identical twins. Blood. 103:4195-4197.

12. Kokame, K., et al. 2002. Mutations and common polymorphisms in ADAMTS13 gene responsible for von Willebrand factor-cleaving protease activity. Proc. Natl. Acad. Sci. U. S. A. 99:11902-11907.

13. Veyradier, A., et al. 2004. Ten candidate ADAMTS13 mutations in six French families with congenital thrombotic thrombocytopenic purpura (Upshaw-Schulman syndrome). J. Thromb.
Haemost. 2:424-429.

14. Dent, J.A., Berkowitz, S.D., Ware, J., Kasper, C.K., and Ruggeri, Z.M. 1990. Identification of a cleavage site directing the immunochemical detection of molecular abnormalities in type IIA von Willebrand factor. Proc. Natl. Acad. Sci. U. S. A. 87:6306-6310.

15. Bruno, K., et al. 2005. Cloning, expression and functional characterization of the full-length murine ADAMTS13. J. Thromb. Haemost. 3:1064-1073.

16. Furlan, M., et al. 1997. Deficient activity of von Willebrand factor-cleaving protease in chronic relapsing thrombotic thrombocytopenic purpura. Blood. 89:3097-3103.

17. Furlan, M., et al. 1998. von Willebrand factor-cleaving protease in thrombotic thrombocytopenic purpura and the hemolytic-uremic syndrome. N. Engl. J. Med. 339:1578-1584.

18. Moake, J.L., et al. 1982. Unusually large plasma factor VIII: von Willebrand factor multimers in chronic relapsing thrombotic thrombocytopenic purpura. N. Engl. J. Med. 307:1432-1435.

19. Mohlke, K.L., et al. 1999. Mvwf, a dominant modifier of murine von Willebrand factor, results from altered lineage-specific expression of a glycosyltransferase. Cell. 96:111-120.

20. Savage, B., Almus-Jacobs, F., and Ruggeri, Z.M. 1998. Specific synergy of multiple substrate-receptor interactions in platelet thrombus formation under flow. Cell. 94:657-666.

21. Andre, P., et al. 2000. Platelets adhere to and translocate on von Willebrand factor presented by endothelium in stimulated veins. Blood. 96:3322-3328.

22. Dong, J.F., et al. 2002. ADAMTS-13 rapidly cleaves newly secreted ultralarge von Willebrand factor multimers on the endothelial surface under flowing conditions. Blood. 100:4033-4039.

23. George, J.N. 2000. How I treat patients with thrombotic thrombocytopenic purpura-hemolytic uremic syndrome. Blood. 96:1223-1229.

24. Ray, P.E., and Liu, X.H. 2001. Pathogenesis of Shiga toxin-induced hemolytic uremic syndrome. Pediatr. Nephrol. 16:823-839.

25. Harvey, P.J., Keightley, A.M., Lam, Y.M., Cameron, C., and Lillicrap, D. 2000. A single nucleotide polymorphism at nucleotide-1793 in the von Willebrand factor (VWF) regulatory region is associated with plasma VWF: Ag levels. Br. J. Haematol. 109:349-353.

26. Banno, F., Kaminaka, K., Soejima, K., Kokame, K., and Miyata, T. 2004. Identification of strain-specific variants of mouse Adamts 13 gene encoding von Willebrand factor-cleaving protease. J. Biol. Chem. 279:30896-30903.

27. Singer, J.B., et al. 2004. Genetic dissection of complex traits with chromosome substitution strains of mice. Science. 304:445-448.

28. Nadeau, J.H., Singer, J.B., Matin, A., and Lander, E.S. 2000. Analysing complex genetic traits with chromosome substitution strains. Nat. Genet. 24:221-261.

29. Matsumoto, M., Yagi, H., Ishizashi, H., Wada, H., and Fujimura, Y. 2004. The Japanese experience with thrombotic thrombocytopenic purpura-hemolytic uremic syndrome. Semin. Hematol. 41:68-74.

30. Williams, T.N., et al. 1996. High incidence of malaria in alpha-thalassaemic children. Nature. 383:522-525

31. Pennisi, E. 2001. Genes and disease. Genetic change wards off malaria. Science. 294:1439.

32. Pier, G.B., et al. 1998. Salmonella typhi uses CFTR to enter intestinal epithelial cells. Nature. 393:79-82.

33. Gabriel, S.E., Brigman, K.N., Koller, B.H., Boucher, R.C., and Stutts, M.J. 1994. Cystic fibrosis heterozygote resistance to cholera toxin in the cystic fibrosis mouse model. Science. 266:107-109.

34. Breslow, J.L. 1996. Mouse models of atherosclerosis. Science. 272:685-688.

35. Cui, J., O'Shea, K.S., Purkayastha, A., Saunders, T.L., and Ginsburg, D. 1996. Fatal haemorrhage and incomplete block to embryogenesis in mice lacking coagulation factor V. Nature. 384:66-68.

36. Kokame, K., Matsumoto, M., Fujimura, Y., and Miyata, T. 2004. VWF73, a region from D1596 to R1668 of von Willebrand factor, provides a minimal substrate for ADAMTS-13. Blood. 103:607-612.

37. Krizek, D.R., and Rick, M.E. 2000. A rapid method to visualize von willebrand factor multimers by using agarose gel electrophoresis, immunolocalization and luminographic detection. Thromb. Res. 97:457-462.

38. Mohlke, K.L., et al. 1996. A novel modifier gene for plasma von Willebrand factor level maps to distal mouse chromosome 11. Proc. Natl. Acad. Sci. U. S. A 93:15352-15357.

39. R Development Core Team. 2004. R: a language and environment for statistical computing. $\mathrm{R}$ Foundation for Statistical Computing. Vienna, Austria. http://www.R-project.org. 